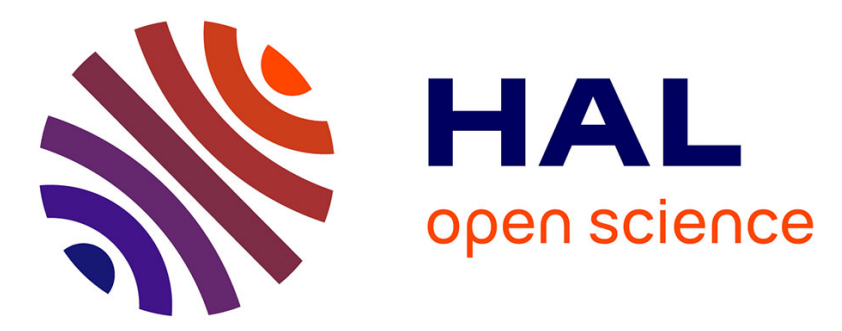

\title{
Mitochondrial function and apoptotic susceptibility in aging skeletal muscle
}

Béatrice Chabi, Vladimir Ljubicic, Keir J. Menzies, Julianna H. Huang, Ayesha Saleem, David A. Hood

\section{To cite this version:}

Béatrice Chabi, Vladimir Ljubicic, Keir J. Menzies, Julianna H. Huang, Ayesha Saleem, et al.. Mitochondrial function and apoptotic susceptibility in aging skeletal muscle. Aging Cell, 2008, 7 (1), pp.2-12. 10.1111/j.1474-9726.2007.00347.x . hal-02665183

\section{HAL Id: hal-02665183 \\ https://hal.inrae.fr/hal-02665183}

Submitted on 31 May 2020

HAL is a multi-disciplinary open access archive for the deposit and dissemination of scientific research documents, whether they are published or not. The documents may come from teaching and research institutions in France or abroad, or from public or private research centers.
L'archive ouverte pluridisciplinaire HAL, est destinée au dépôt et à la diffusion de documents scientifiques de niveau recherche, publiés ou non, émanant des établissements d'enseignement et de recherche français ou étrangers, des laboratoires publics ou privés.

\section{(c)(1)}

Distributed under a Creative Commons Attribution| 4.0 International License 


\section{Mitochondrial function and apoptotic susceptibility in aging skeletal muscle}

\author{
Béatrice Chabi, ${ }^{2 *}$ Vladimir Ljubicic, ${ }^{1}$ \\ Keir J. Menzies, ${ }^{2}$ Julianna H. Huang, ${ }^{1}$ Ayesha Saleem ${ }^{1}$ \\ and David A. Hood ${ }^{1,2}$ \\ ${ }^{1}$ School of Kinesiology and Health Science and ${ }^{2}$ Department of \\ Biology, York University, Toronto, Ontario, Canada M3J 1P3
}

\section{Summary}

During aging, skeletal muscle undergoes sarcopenia, a condition characterized by a loss of muscle cell mass and alterations in contractile function. The origin of these decrements is unknown, but evidence suggests that they can be partly attributed to mitochondrial dysfunction. To characterize the nature of this dysfunction, we investigated skeletal muscle contractile properties, subsarcolemmal (SS) and intermyofibrillar (IMF) mitochondrial biogenesis and function, as well as apoptotic susceptibility in young (6 months old) and senescent (36 months old) Fischer 344 Brown Norway rats. Muscle mass and maximal force production were significantly lower in the 36-month group, which is indicative of a sarcopenic phenotype. Furthermore, contractile activity in situ revealed greater fatigability in the 36-month compared to the 6-month animals. This decrement could be partially accounted for by a $30 \%$ lower mitochondrial content in fast-twitch muscle from 36-month animals, as well as lower protein levels of the transcriptional coactivator peroxisome proliferator-activated receptor $\gamma$ coactivator$1 \alpha$. Enzyme activities and glutamate-induced oxygen consumption rates in isolated SS and IMF mitochondria were similar between age groups. However, mitochondrial reactive oxygen species (ROS) production during state 3 respiration was $\sim 1.7$-fold greater in mitochondria isolated from 36-month compared to 6-month animals, and was accompanied by a 1.8-fold increase in the DNA repair enzyme 8-oxoguanine glycosylase 1 in fast-twitch muscle. Basal rates of release of cytochrome $c$ and endonuclease G in SS mitochondria were 3.5- to 7-fold higher from senescent animals. These data suggest that the age-related sarcopenia and muscle fatigability are associated with enhanced ROS production, increased mitochondrial

Correspondence

Dr David A. Hood, School of Kinesiology and Health Science, York University, Toronto, Ontario, Canada M3J 1P3. Tel.: (416) 7362100 ext. 66640;

fax: (416) 736 5698; e-mail: dhood@yorku.ca

*Present address: INRA - UMR 866 Differenciation Cellulaire et Croissance, Bât 22-2 place Pierre Viala, 34060 Montpellier Cedex 1, France.

Accepted for publication 21 September 2007 apoptotic susceptibility and reduced transcriptional drive for mitochondrial biogenesis.

Key words: contractile activity; mitochondrial biogenesis; oxidative stress; permeability transition pore; sarcopenia; subsarcolemmal and intermyofibrillar mitochondria.

\section{Introduction}

Mitochondria are intimately linked to the proper function of skeletal muscle, as these organelles constitute the main energy supply in contracting muscle. Evidence has shown that decrements in the oxidative capacity of aged skeletal muscle is associated with the impairment of mitochondrial function, such as reduced electron transport chain complex activity (Trounce et al., 1989; Conley et al., 2000; Hagen et al., 2004) or adenosine triphosphate (ATP) synthesis (Drew et al., 2003). However, discrepancies regarding the certainty of aging-induced limitations in mitochondrial function arise when considering confounding variables such as physical activity (Barrientos et al., 1996), or the type of samples used in the study (e.g. whole muscle homogenates vs. isolated mitochondria). A number of investigations performed with isolated mitochondria have not revealed any deterioration in mitochondrial activity with age (Rasmussen et al., 2003; Tonkonogi et al., 2003). Studies examining mitochondrial adaptations to aging should take into account the potential contribution of the subsarcolemmal (SS) and intermyofibrillar (IMF) mitochondrial subfractions when assessing organelle composition and function. It has previously been shown that each mitochondrial population displays unique biochemical and functional properties (Cogswell et al., 1993; Takahashi \& Hood, 1996; Bizeau et al., 1998; Ljubicic et al., 2004; Koves et al., 2005). Indeed, studies in cardiac muscle have reported that IMF and SS mitochondria adapt differently during the aging process, with the IMF subfraction showing a reduced capacity for oxygen consumption $\left(\mathrm{VO}_{2}\right)$ concomitant with increased reactive oxygen species (ROS) production compared to SS mitochondria (Fannin et al., 1999; Judge et al., 2005). To date, only limited evidence exists supporting the hypothesis that SS and IMF mitochondrial subfractions possess different functional characteristics in senescent skeletal muscle (Farrar et al., 1981).

Several mechanisms have been proposed as causing of age-related muscle fibre atrophy, including enhanced muscle proteolysis (Mosoni et al., 1999), the accumulation of defective mitochondria (Wanagat et al., 2001; Bua et al., 2002) and apoptosis. Recent evidence has shown that mitochondria are involved in promoting protein degradation in skeletal muscle from older compared to younger animals (Martin et al., 2007). An increased incidence of apoptosis, as well as the expression of apoptotic proteins, has been reported in aged skeletal muscle 
(Dirks \& Leeuwenburgh, 2002, 2004); however, the mechanisms involved in the mitochondrial-triggered apoptotic process have not been fully investigated.

Reactive oxygen species may play a role in promoting apoptosis, as they are known to activate the opening of the mitochondrial permeability transition pore (mtPTP) and facilitate the release of proapoptotic proteins such as cytochrome $c$, endonuclease $\mathrm{G}$ or apoptosis inducing factor (AIF) into the cytosol (Adhihetty \& Hood, 2003). However, the levels of oxidant production, as well as the ability of ROS to initiate the opening of the mtPTP in aged skeletal muscle mitochondria, have not been fully addressed. Thus, the purpose of this study was to assess mitochondrial composition and function in aged skeletal muscle. Furthermore, we also investigated parameters regulating mitochondrial ROS production and mitochondrial apoptotic susceptibility in senescent muscle. We hypothesized that mitochondrial function would be impaired, and that mitochondrial apoptotic susceptibility would be increased in aging skeletal muscle, coinciding with the extent of muscle atrophy.

\section{Results}

\section{Animal characteristics}

As expected, senescent animals had a 33\% greater body mass than their young counterparts (Table 1). This was associated with an increase in the heart weight to body weight ratio of $14 \%(P<0.05)$ in senescent animals, reflecting a modest cardiac hypertrophy due to aging (Fig. 1B). In contrast, the muscle to body mass ratios were reduced by $44 \%, 53 \%$ and $66 \%$ for soleus, plantaris and tibialis anterior, respectively $(P<0.001$; Fig. 1B), in senescent animals, reflecting muscle type-specific sarcopenia when compared with young animals.

\section{Muscle contractile properties}

To evaluate the effect of the age-induced reduction in tibialis anterior mass on muscle contractile properties, we measured the peak tetanic force and muscle fatigue resistance over a 5min acute contractile activity protocol. The tetanic force expressed per unit of body mass, as well as per unit tibialis anterior mass, were $75 \%$ and $38 \%(P<0.05)$ lower in senescent compared to young animals, respectively (Table 1). During the in situ $1 \mathrm{~Hz}$

Table 1 Animal and muscle characteristics

\begin{tabular}{llll}
\hline $\begin{array}{l}\text { Age } \\
\text { (months) }\end{array}$ & BM (g) & $\begin{array}{l}\text { TET force/BM } \\
\left(\mathrm{mN} \mathrm{g}^{-1}\right)\end{array}$ & $\begin{array}{l}\text { TET force/TAM } \\
\left(\mathrm{mN} \mathrm{mg} \mathrm{m}^{-1}\right)\end{array}$ \\
\hline 6 & $395 \pm 10$ & $19.5 \pm 0.76$ & $10.23 \pm 0.48$ \\
36 & $527 \pm 11^{*}$ & $4.87 \pm 0.45^{*}$ & $6.40 \pm 0.45^{\star}$ \\
\hline
\end{tabular}

Values are means $\pm \mathrm{SE} ; n=13 /$ group.

$\mathrm{BM}$, body mass; TAM, tibialis anterior mass; TET force/BM, maximal tetanic force production per unit BM.

${ }^{*} P<0.05,6$ months old vs. 36 months old.
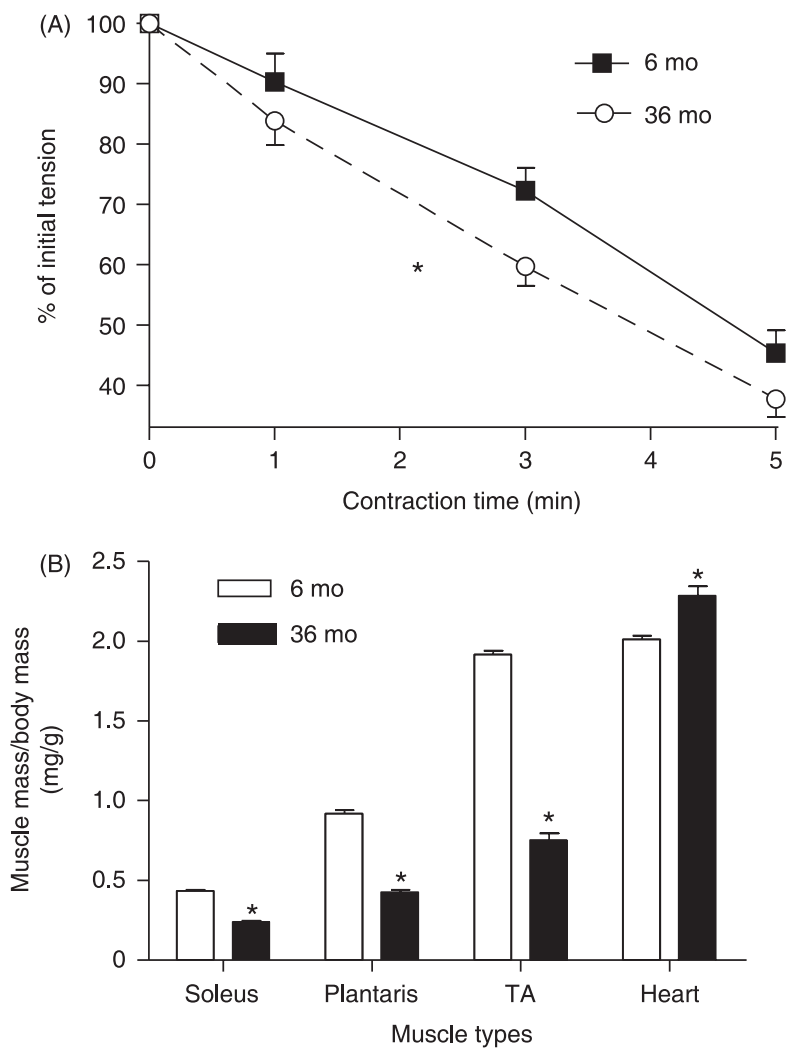

Fig. 1 Effect of age on muscle characteristics and endurance performance. (A) Tibialis anterior force output during in situ stimulation. Force in 6-monthold and 36-month-old rats is expressed as a percent of initial tension during the 5-min stimulation protocol. Values are expressed as means $\pm \mathrm{SE} ; n=8$ for each group. Analysis of variance (ANOVA), ${ }^{*} P<0.05$ vs. 6 months. (B) Muscle mass is expressed per unit of body weight in 6-month-old and 36-month-old animals. Values are means $\pm \mathrm{SE} ; n=13$ for each group. ${ }^{*} P<0.001$ vs. 6 months.

stimulation protocol, both groups displayed a decrease in relative force output; however, both the extent of fatigue at each time-point and the rate of force decline were significantly greater $(P<0.05)$ in the aged animals (Fig. 1A).

\section{Mitochondrial yield, citrate synthase activity and oxygen consumption}

Consistent with previous results (Cogswell et al., 1993; Bizeau et al., 1998; Bezaire et al., 2004), IMF mitochondrial protein yield was $20 \%$ higher $(P<0.05)$ compared to the SS subfraction in both age groups (Table 2). There was no effect of age on the extractable yield of mitochondrial protein per gram of tissue. The IMF subfraction exhibited $50 \%$ and $30 \%$ higher $(P<0.05)$ citrate synthase (CS) activity compared to SS mitochondria at 6 and 36 months, respectively (Table 2 ). The activity of this enzyme was not different between young and senescent animals in either SS or IMF mitochondria. A similar pattern of results was observed for the activity of cytochrome c oxidase (COX), an inner membrane enzyme. No effect of age was observed.

In agreement with previous studies (Cogswell et al., 1993; Ljubicic et al., 2004), state 4 (glutamate-stimulated) and state 3 
Table 2 Mitochondrial yield, respiration rates and enzyme activity in SS and IMF subfractions

\begin{tabular}{|c|c|c|c|c|c|c|}
\hline & \multicolumn{3}{|l|}{6 months } & \multicolumn{3}{|l|}{36 months } \\
\hline & SS & $\mathrm{IMF}$ & Fold & SS & IMF & Fold \\
\hline Mitochondrial protein yield ( $\mathrm{mg} \mathrm{g}^{-1}$ muscle) & $1.35 \pm 0.1$ & $1.67 \pm 0.1$ & 1.3 & $1.46 \pm 0.1$ & $1.74 \pm 0.1$ & 1.2 \\
\hline $\mathrm{CS}$ activity $\left(\mathrm{U} \mathrm{mg} \mathrm{m}^{-1}\right)$ & $44.0 \pm 3.2$ & $67.3 \pm 4.9$ & 1.5 & $50.3 \pm 2.1$ & $65.9 \pm 5.1$ & 1.3 \\
\hline COX activity $\left(\mathrm{U} \mathrm{mg}^{-1}\right)$ & $0.60 \pm 0.1$ & $0.83 \pm 0.1$ & 1.4 & $0.63 \pm 0.1$ & $0.80 \pm 0.1$ & 1.3 \\
\hline State 4 respiration $\left(n\right.$ atoms $\mathrm{O}_{2} \mathrm{~min}^{-1} \mathrm{mg}^{-1}$ ) & $7.9 \pm 2.0$ & $25.0 \pm 7.0$ & 3.2 & $10.1 \pm 2.2$ & $21.7 \pm 6.4$ & 2.1 \\
\hline State 3 respiration ( $n$ atoms $\mathrm{O}_{2} \mathrm{~min}^{-1} \mathrm{mg}^{-1}$ ) & $93.9 \pm 17$ & $180.9 \pm 29$ & 1.9 & $80.3 \pm 17$ & $133.7 \pm 22$ & 1.7 \\
\hline $\mathrm{RCR}$ & $13.6 \pm 1.5$ & $10.8 \pm 2.9$ & 0.8 & $8.1 \pm 0.6^{*}$ & $8.5 \pm 1.2^{*}$ & 1.1 \\
\hline
\end{tabular}

Values are reported as means $\pm \mathrm{SE} ; n=8-13$ /group.

SS, subsarcolemmal; IMF, intermyofibrillar; fold, fold difference of IMF over SS; CS, citrate synthase; COX, cytochrome c oxidase; RCR, respiratory control ratio; $\mathrm{U} \mathrm{mg}{ }^{-1}$, units of activity per $\mathrm{mg}$ of mitochondrial protein.

${ }^{*} P<0.05,6$ months old vs. 36 months old; $P<0.05$, SS vs. IMF mitochondria.

(glutamate and adenosine diphosphate-stimulated) respiration rates in IMF mitochondria isolated from the young animals were significantly greater than those observed in the SS subfraction (Table 2). In the senescent group, IMF mitochondrial respiration rates were also significantly elevated compared to SS mitochondrial oxygen consumption levels; however, the fold difference between the subfractions was lower when compared to the young group. There were no significant differences between young and old animals with respect to state 3 or state 4 respiration in either subfraction (Table 2). However, the respiratory control ratios, which is indicative of the coupling between respiration and oxidative phosphorylation, were $40 \%$ and $21 \%$ lower $(P<0.05)$ in SS and IMF mitochondria harvested from the senescent group as compared to the respiratory control ratios obtained from mitochondria isolated from the young animals.

\section{Age effects on skeletal muscle COX activity and transcription factor protein expression}

Cytochrome oxidase activity was measured in tissue homogenates from soleus and plantaris muscles (Fig. 2A). Enzyme activities in the soleus and plantaris from the senescent animals were $30 \%$ lower $(P<0.05)$ compared to those tissues isolated from young animals, which is indicative of a reduced mitochondrial content per gram of muscle. In addition, enzyme activities were approximately $40 \%$ higher $(P<0.05)$ in soleus compared to plantaris in both animal groups. We also examined the protein levels of the transcriptional coactivator peroxisome proliferatoractivated receptor $\gamma$ coactivator- $1 \alpha$ (PGC-1 $\alpha$ ) (Fig. 2B), and the primary mitochondrial DNA (mtDNA) transcription factor Tfam in soleus and plantaris muscle homogenates (Fig. 2C). Similar to the changes in COX activity, PGC-1 $\alpha$ expression was lower in the tissues obtained from the senescent animals. This reduction was more pronounced in the soleus $(-65 \%$; $P<0.05)$ compared to the plantaris $(-25 \% ; P<0.05)$. In contrast, Tfam protein content was $40 \%$ higher $(P<0.05)$ in the soleus and $12 \%$ higher $(P<0.05)$ in the plantaris muscles from senescent rats compared to their young counterparts.

\section{Mitochondrial membrane potential, composition, and ROS production}

As mitochondrial respiration and ATP production depend on membrane potential $(\Delta \psi)$ across the mitochondrial inner membrane, we used flow cytometry to examine SS and IMF mitochondrial $\Delta \psi$ in young and aged animals (Fig. 3A). As reported previously (Adhihetty et al., 2005), $\Delta \psi$ in the IMF subfraction was $60 \%$ lower $(P<0.05)$ relative to SS mitochondria isolated from the young animals. In the senescent group, the $\Delta \psi$ in SS mitochondria was $47 \%$ lower $(P<0.05)$ compared to the young animals, while the $\Delta \psi$ in IMF mitochondria was not different between the two age groups. To explore the relationship between $\Delta \psi$ and organelle function, we evaluated ROS production in isolated, respiring mitochondrial subfractions. ROS production per $n$ atom of $\mathrm{O}_{2}$ consumed during state 3 respiration was 1.6- to 1.8 -fold greater $(P<0.05)$ in SS and IMF mitochondria isolated from senescent animals compared to their young counterparts (Fig. 3B). SS and IMF mitochondrial ROS production during state 4 respiration was similar between age groups (data not shown). Protein content of the mitochondrial antioxidant enzyme $\mathrm{Mn}^{2+}$-superoxide dismutase (MnSOD) was not different between SS and IMF subfractions or young and senescent animals (Fig. 3C). To determine whether aging had any impact on mitochondrial phospholipid composition, cardiolipin content was estimated using flow cytometry (Fig. 3D). The amount of cardiolipin was $20-30 \%$ higher $(P<0.05)$ in SS mitochondria compared to the IMF subfraction; however, no effect of age was observed in either subfraction. In addition, the expression of the DNA repair enzyme oxo-guanine glycosylase (Ogg1) was also similar between young and senescent animals in both soleus and plantaris (Fig. 3E).

\section{Effect of age on mtPTP kinetics and composition}

Oxidative stress and mitochondrially triggered apoptosis are linked through the ROS-induced opening of the mtPTP. Therefore, we examined the kinetics of mtPTP opening (i.e. Vmax and time 

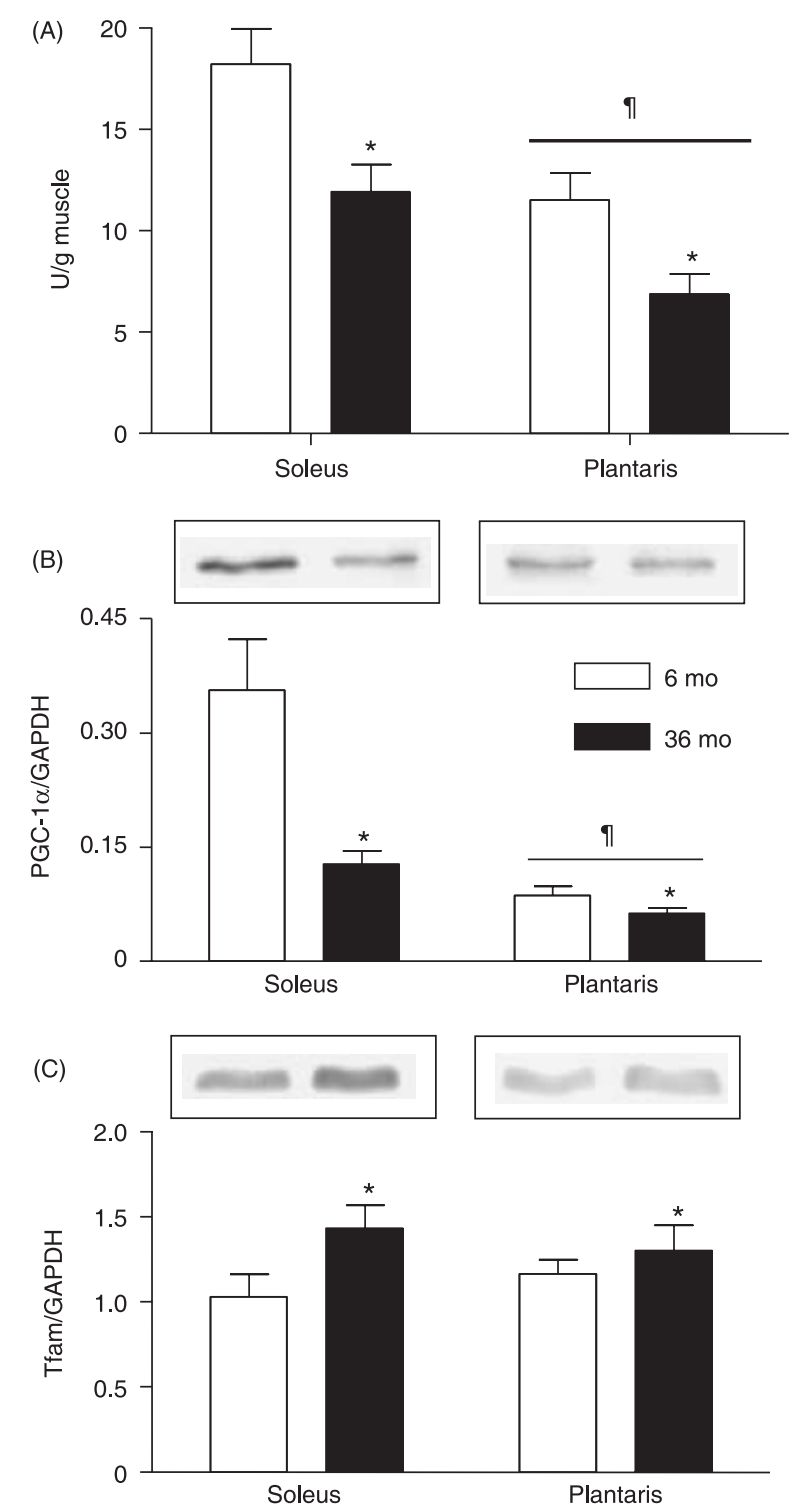

Fig. 2 Age effect on mitochondrial biogenesis in skeletal muscle. (A) Cytochrome c oxidase (COX) activity was expressed as unit per gram of tissue in soleus and plantaris muscles from 6-month-old and 36-month-old animals. ${ }^{*} P<0.05$ vs. 6 months; $P<0.05$ vs. soleus. Western blot analysis and representative blots of peroxisome proliferator-activated receptor $\gamma$ coactivator-1 $\alpha$ (PGC-1 $\alpha)(B)$ and Tfam (C) protein content in soleus and plantaris muscles from 6-month-old and 36-month-old rats. PGC-1 $\alpha$ and Tfam protein expression are corrected for glyceraldehyde-3 phosphate dehydrogenase (GAPDH) protein content. Values are means $\pm \mathrm{SE} ; n=8-11$ for each group. Analysis of variance (ANOVA), ${ }^{*} P<0.05$ vs. 6 months; I $P<0.05$ vs. soleus.

to Vmax) in both SS and IMF mitochondria of young and senescent animals. The Vmax of pore opening was significantly greater for IMF mitochondria relative to the SS subfraction in both age groups (Fig. 4A). In IMF mitochondria, the Vmax was similar in the young and senescent animals. However, the Vmax measured in the SS subfraction was 40\% lower $(P<0.05)$ from aged skeletal muscle relative to the young animals. In contrast, the time to Vmax was not significantly different between SS and
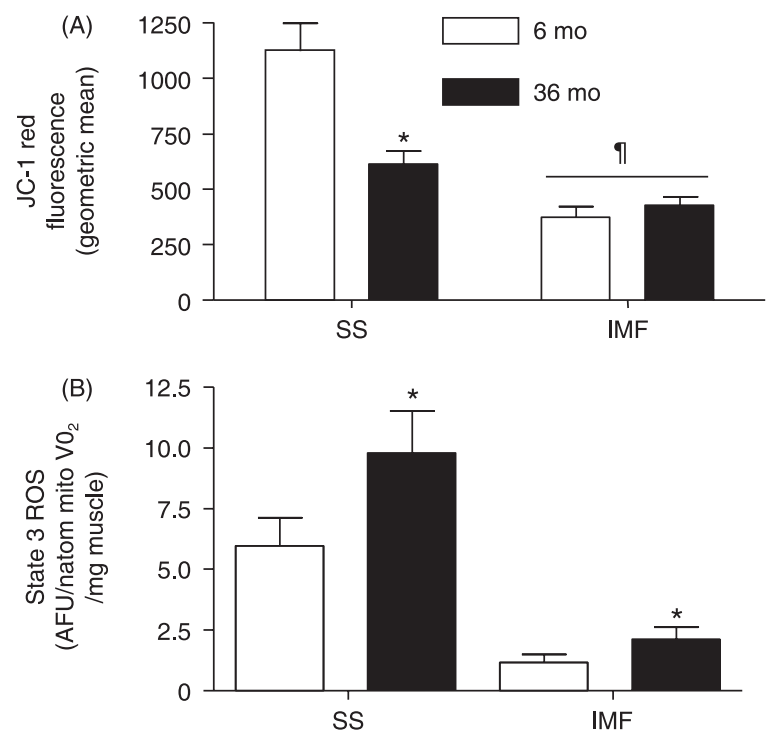

(C)
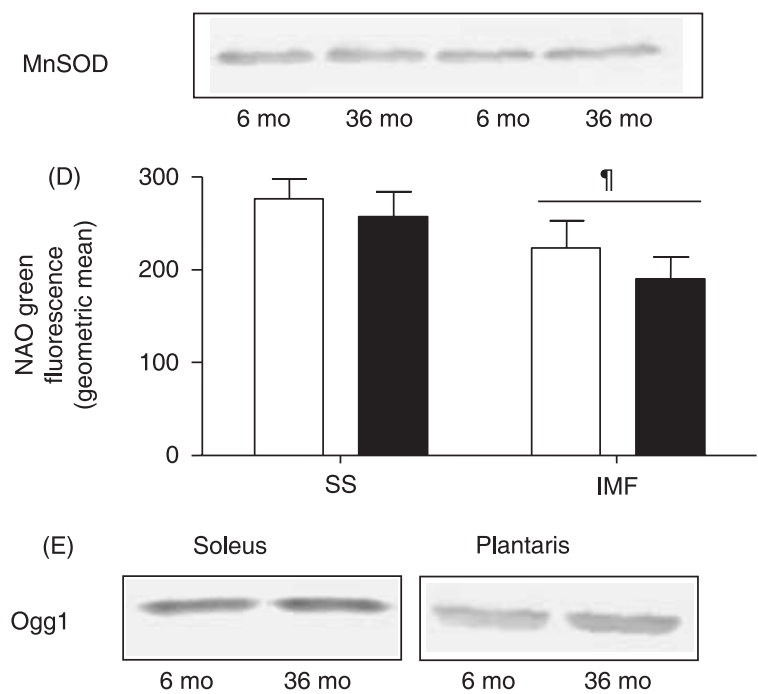

Fig. 3 (A) Mitochondrial membrane potential of subsarcolemmal (SS) and intermyofibrillar (IMF) subfractions isolated from 6-month-old (open bars) and 36-month-old (closed bars) animals, represented as the mean geometric red fluorescence of the probe JC-1 quantified by flow cytometric analysis. (B) Mitochondrial reactive oxygen species (ROS) production (arbitrary fluorescent units, AFU) per $n$ atom $\mathrm{O}_{2}$ consumed in SS and IMF subfractions from 6-month-old and 36-month-old rats during state 3 (glutamate and adenosine diphosphate-stimulated) respiration. (C) Western blot analysis of MnSOD protein content in SS and IMF mitochondria from 6-month-old and 36-month-old rats. (D) Determination of mitochondrial cardiolipin content using quantification of the mean geometric green fluorescence of the probe 10-N-Nonyl-3,6-bis(dimethylamino) acridine orange (NAO) by flow cytometric analysis of SS and IMF mitochondria from 6-month-old and 36-month-old animals. (E) Representative Western blots of Ogg1 protein content in soleus and plantaris muscles from 6-month-old and 36-month-old animals. Values are means $\pm \mathrm{SE} ; n=7-8$ for each group. Analysis of variance (ANOVA), ${ }^{*} P<0.05$ vs. 6 months; $\uparrow P<0.05$ vs. SS mitochondria.

IMF mitochondria, and there was no effect of age (Fig. 4B). To evaluate whether mtPTP opening kinetics were influenced by its composition, we assessed the protein contents of voltagedependant anion channel (VDAC), adenine nucleotide translocase 

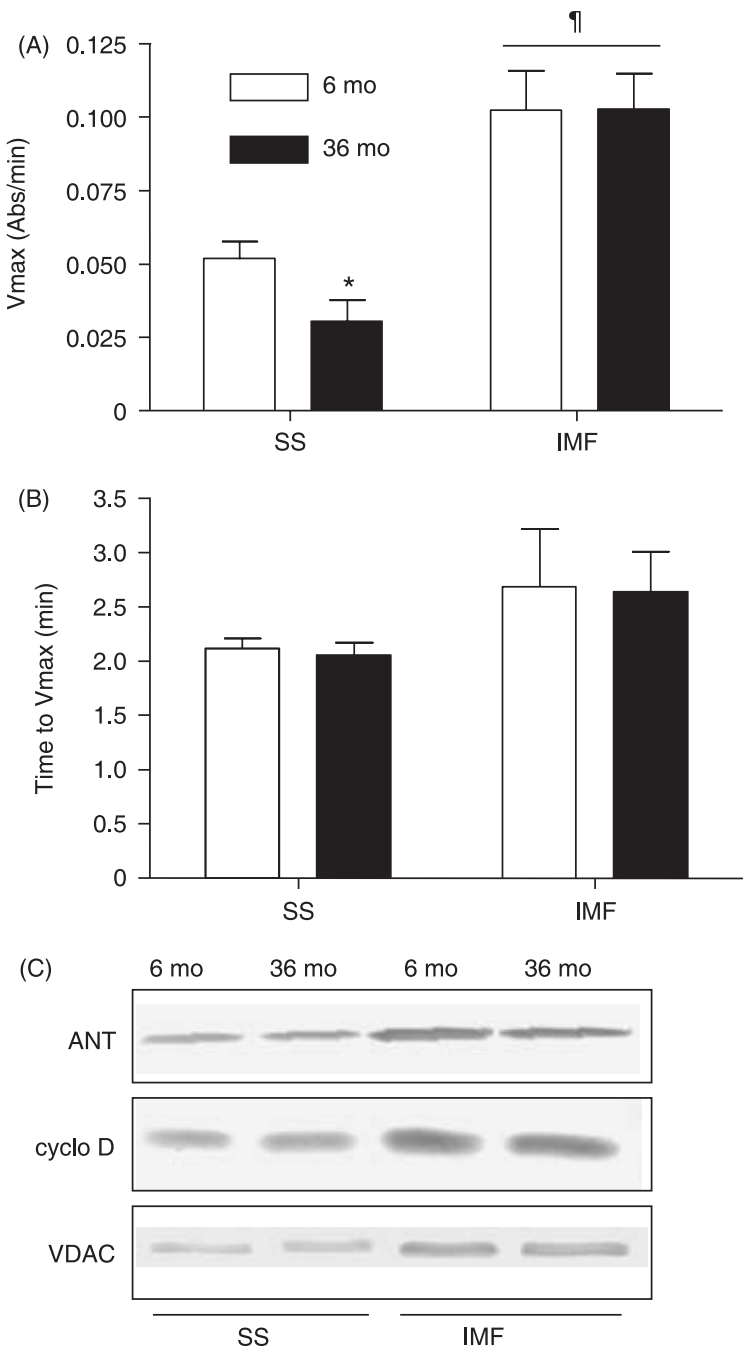

Fig. 4 Mitochondrial permeability transition pore (mtPTP) characteristics of subsarcolemmal (SS) and intermyofibrillar (IMF) mitochondria from 6-monthold and 36-month-old rats. (A) Maximal rate (Vmax) of mtPTP opening and (B) time to Vmax following treatment of mitochondria with $\mathrm{CaCl}_{2}$ and $t$-BuOOH. (C) Western blot analysis of mtPTP components adenine nucleotide translocase (ANT), cyclophilin D (cyclo D) and voltage-dependent anion chanel (VDAC) in SS and IMF mitochondria. Values are means $\pm \mathrm{SE}$; $n=6-8$ per group. Analysis of variance (ANOVA), ${ }^{*} P<0.05$ vs. 6 months; П $P<0.05$ vs. SS mitochondria.

(ANT) and cyclophilin D, three integral constituents of the mtPTP. These proteins were more abundant in IMF mitochondria compared to the SS subfraction isolated from both age groups; however, aging had no effect on the expression of these mtPTP components (Fig. 4C).

\section{Mitochondrial cytochrome c content and release}

To further characterize the susceptibility to mitochondrially triggered apoptosis in senescent skeletal muscle, we measured the contents of key apoptotic proteins housed within the organelle, as well as their capacity to be released from mitochondria following exogenous hydrogen peroxide $\left(\mathrm{H}_{2} \mathrm{O}_{2}\right)$ treatment. Endogenous levels of mitochondrial cytochrome $c$
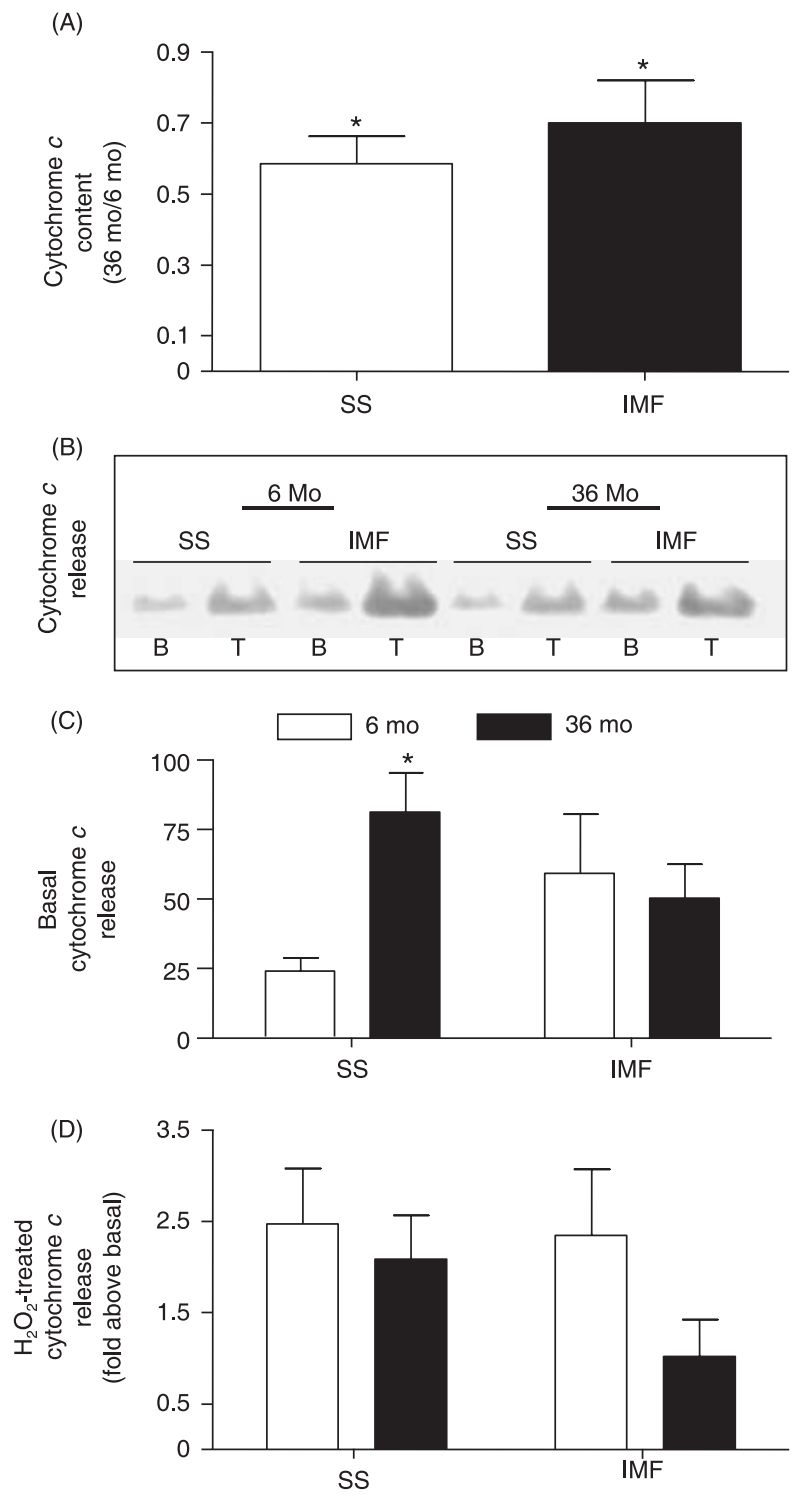

(E)

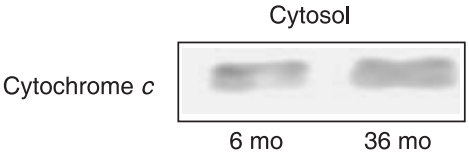

Fig. 5 Mitochondrial cytochrome $\mathrm{c}$ content and $\mathrm{H}_{2} \mathrm{O}_{2}$-induced protein release. (A) Cytochrome c content in SS and IMF mitochondria isolated from skeletal muscle of 6-month-old and 36-month-old animals. (B) Representative Western blot of cytochrome $c$ released from subsarcolemmal (SS) and intermyofibrillar (IMF) mitochondrial samples in the absence (B, basal) or presence ( $\mathrm{T}$, treated) of $\mathrm{H}_{2} \mathrm{O}_{2}$. (C) Cytochrome $\mathrm{c}$ release from untreated $\mathrm{SS}$ and IMF mitochondria corrected for endogenous mitochondrial cytochrome c content. (D) Cytochrome $\mathrm{c}$ release from SS and IMF mitochondria following treatment with $\mathrm{H}_{2} \mathrm{O}_{2}$, expressed as a fold increase above the basal, untreated release rates. (E) Western blot of cytochrome $\mathrm{c}$ protein levels in muscle cytosolic fractions from 6-month-old and 36-month-old groups. Values are means $\pm \mathrm{SE} ; n=5-$ 7 per group. Analysis of variance (ANOVA), ${ }^{*} P<0.05$ vs. 6 -month-old animals

(Fig. 5A) were $30-40 \%$ lower $(P<0.05)$ in IMF and SS subfractions in senescent, compared to young animals. Within each age group, basal rates of cytochrome $c$ release were similar in SS and IMF mitochondria (Fig. 5B,C). However, cytochrome $c$ release 
under basal conditions was 3.5-fold higher $(P<0.05)$ in SS mitochondria obtained from senescent compared to young animals (Fig. 5B,C). There was no effect of age on cytochrome $c$ release under basal conditions for the IMF subfraction (Fig. 5B,C). Following treatment of isolated mitochondria with $\mathrm{H}_{2} \mathrm{O}_{2}$, both mitochondrial subfractions from young and senescent animals released up to 1.5- to 2.5-fold more cytochrome c (Fig. 5B,D). There was no significant effect of age. In addition, steady-state levels of cytosolic cytochrome $c$ were similar between age groups (Fig. 5E).

\section{Endonuclease G content and release from SS and IMF mitochondria}

Similar to cytochrome $c$, endonuclease $\mathrm{G}$ content (Fig. 6A) was 40-60\% lower $(P<0.05)$ in SS and IMF mitochondria isolated from senescent compared to young animals. Within each age group, basal rates of endonuclease $\mathrm{G}$ release were similar in IMF and SS mitochondria. However, under basal conditions, endonuclease $\mathrm{G}$ release from mitochondria was two- to sevenfold higher $(P<0.05)$ in IMF and SS subfractions harvested from aged relative to young animals (Fig. $6 \mathrm{~B}, \mathrm{C}$ ). $\mathrm{H}_{2} \mathrm{O}_{2}$-induced endonuclease $\mathrm{G}$ release from $\mathrm{SS}$ and IMF mitochondria was similar between age groups (Fig. 6B,D), and did not differ between mitochondrial subfractions. The concentration of cytosolic endonuclease $\mathrm{G}$ protein was also similar between young and aged animals (Fig. 6E).

\section{Discussion}

Muscle atrophy occurs with age, a process known as sarcopenia. Mitochondria are likely to be intimately involved in contributing to this, either via decrements in energy supply, or via mitochondrially mediated proteolysis or apoptosis. To investigate this directly, we designed a study to evaluate both mitochondrial energy supply and indices of mitochondrial function related to apoptosis, along with decrements in muscle mass and contractile function. Although several studies have previously examined organelle function in skeletal muscle of aged individuals, the results of these assessments are confounded in the literature by a lack of uniform methodologies to measure mitochondrial function, using whole tissue homogenates instead of purified mitochondrial fractions. In addition, no previous study has considered skeletal muscle SS and IMF mitochondrial respiratory and apoptotic adaptations during later senescence in the wellknown model of aging, the Fischer Brown Norway rat (Turturro et al., 1999). We compared young adult (6 months old) to senescent (35-36 months old) animals, which present with a high degree of sarcopenia, as evidenced by a $60-70 \%$ lower hind limb muscle mass (Table 1). As expected, these animals also displayed a reduced maximal tetanic force output per gram of muscle, and increased fatigability, indicating that the quality of aged skeletal muscle is also markedly reduced.

The increase in muscle fatigability is undoubtedly related in large measure to the reduction in overall mitochondrial content,

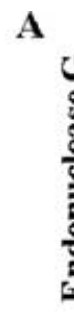

B

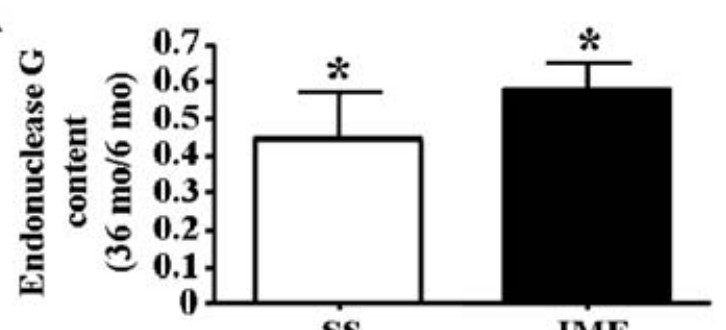

")

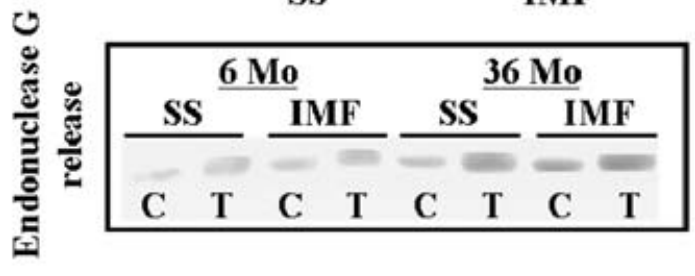

C
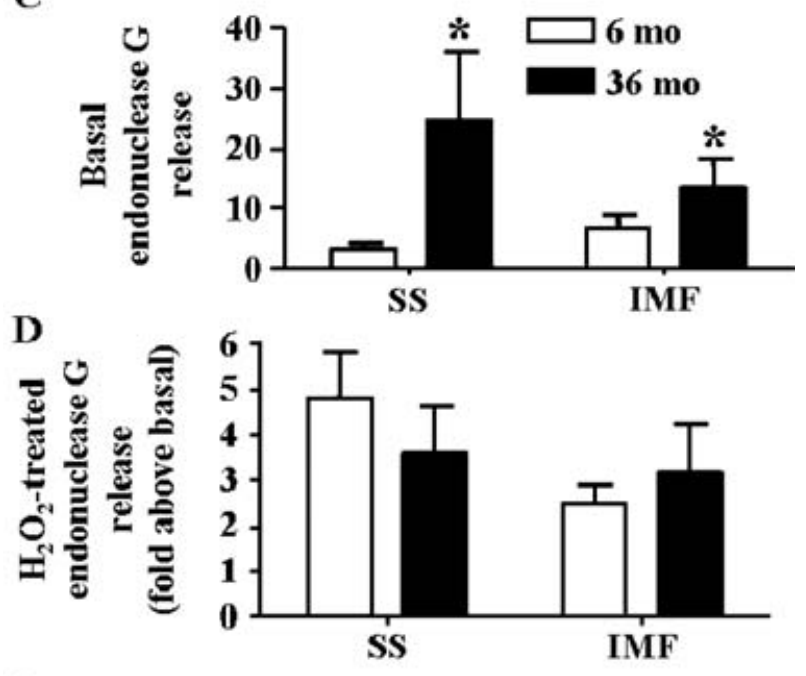

E

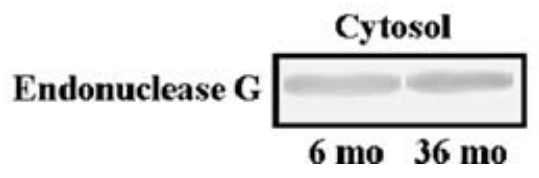

Fig. 6 Mitochondrial endonuclease $\mathrm{G}$ content and $\mathrm{H}_{2} \mathrm{O}_{2}$-induced protein release. (A) Endonuclease $\mathrm{G}$ content in SS and IMF mitochondria isolated from skeletal muscle of 6-month-old and 36-month-old animals. (B) Representative Western blot of endonuclease $\mathrm{G}$ released from subsarcolemmal (SS) and intermyofibrillar (IMF) mitochondrial samples in the absence (B, basal) or presence ( $\mathrm{T}$, treated) of $\mathrm{H}_{2} \mathrm{O}_{2}$. (C) Endonuclease $\mathrm{G}$ release from untreated $\mathrm{SS}$ and IMF mitochondria corrected for endogenous mitochondrial endonuclease $\mathrm{G}$ content. (D) Endonuclease $\mathrm{G}$ release from SS and IMF mitochondria following treatment with $\mathrm{H}_{2} \mathrm{O}_{2}$, expressed as a fold increase above the basal, untreated release rates. (E) Western blot of endonuclease $G$ protein levels in muscle cytosolic fractions from 6-month-old and 36-month-old groups. Values are means $\pm \mathrm{SE} ; n=7-8$ per group. Analysis of variance (ANOVA), ${ }^{\star} P<0.05$ vs. 6 -month-old animals.

observed in both fast- and slow-twitch muscle. It is well known that the content of mitochondria is closely correlated with muscular endurance performance (Irrcher et al., 2003). In this respect, the decline in mitochondrial content is more important than possible changes in the composition of individual mitochondria, as COX (complex IV) and CS activities were not different in isolated mitochondria obtained from young and old 
animals. Our results also indicate no difference in the rates of state 4 or state 3 respiration, indicating that the capacity for ATP synthesis in isolated mitochondria remains high in old animals, at least with the respiratory substrates utilized in our study. These results are similar to those reported previously by Farrar et al. (1981). However, the capacity for ATP synthesis per gram of muscle is clearly reduced with age, as a consequence of the decline in mitochondrial content. This is likely due, in part, to the reduction in the expression of the transcriptional coactivator PGC- $1 \alpha$, a protein that contributes substantially to the coordinated transcription of nuclear genes encoding mitochondrial proteins. An indication of $\mathrm{PGC}-1 \alpha$ activity in aging muscle would provide additional insight, and is under investigation. Interestingly, and similar to previous work by Lezza et al. (2001), the expression of Tfam was moderately increased in muscle of aged animals. The increase in the expression of this important transcription factor for mtDNA transcription may be indicative of a compensatory attempt to attenuate the decay in mitochondrial enzyme activity and functional mtDNA content in senescent muscle (Dirks et al., 2006). An understanding of the regulation of the expression of both PGC$1 \alpha$ and Tfam in aged muscle awaits continued evaluation.

Our data provide evidence for subtle alterations in mitochondrial composition and function with age that has implications for cell death. Notably, this included a significant increase in ROS production in both SS and IMF mitochondria, even in the presence of a reduced $\Delta \psi$ in the SS subfraction. This difference in mitochondrial ROS production between young and old animals was similar in IMF and in SS mitochondria. It is likely a consequence of altered electron transport chain complex I or III function in aged skeletal muscle, rather than a decrease in antioxidant capacity, because similar levels of the protein content of MnSOD were observed in young and old animals. A chronic increase in ROS production could lead to further macromolecular damage (e.g. an accumulation of mtDNA mutations), subsequent electron transport chain dysfunction, and respiratory defects in an escalating manner, which is consistent with currently existing free-radical theories of aging. Indeed, the elevated expression of the DNA repair protein Ogg1 in senescent animals suggests that the level of ROS production did reach a critical threshold to produce oxidative stress. This enzyme is considered to be a useful biomarker for oxidative stress (Mo et al., 2006), as it is up-regulated in a variety of tissues (Risom et al., 2003; Nakabeppu et al., 2004; Cortina et al., 2005) when oxidative stress is induced.

The elevated ROS production observed in the present study could provoke the opening of the mtPTP, leading to the release of proapoptotic proteins such as cytochrome $c$ and endonuclease $\mathrm{G}$, and subsequent DNA fragmentation. This is consistent with reports indicating an increased incidence of apoptosis in aged skeletal muscle (Dirks \& Leeuwenburgh, 2002; Siu et al., 2005; Chung \& Ng, 2006; Rice \& Blough, 2006). In SS mitochondria, our data indicate that the release of cytochrome $c$ and endonuclease $G$ was enhanced under basal conditions in senescent as compared to young animals. A similar result was observed for endonuclease $\mathrm{G}$ in the IMF mitochondria from aged animals. These increases in proapoptotic protein release rates could not be attributed to alterations in mtPTP composition between the two age groups, as cyclophilin D, adenine nucleotide translocase and porin concentrations were not different between young and old animals. In addition, mtPTP kinetic differences were not consistent with an enhanced release of these proteins via the mtPTP. Thus, the release of cytochrome $c$ and endonuclease $G$ appears to occur via an alternative route, likely mediated by the mitochondrial apoptosis channel (MAC), regulated by the Bax to $\mathrm{BCl}-2$ ratio (Green \& Reed, 1998; Siu \& Alway, 2005). Previous studies have shown that this ratio is augmented in both the mitochondrial fraction and in whole muscle homogenates from senescent rats (Dirks \& Leeuwenburgh, 2002; Chung \& Ng, 2006). Alternatively, this release may be due to age-dependent differences in the structure of mitochondria from aged animals, possibly brought about by their higher endogenous ROS production, which could induce molecular changes to mitochondrial lipids or proteins that interact with cytochrome $c$ or endonuclease $\mathrm{G}$.

It is interesting to note that the enhanced protein release rates with age were evident in the basal state, in the absence of added exogenous $\mathrm{H}_{2} \mathrm{O}_{2}$. These data clearly indicate the greater potential of mitochondria from aged animals to release proapoptotic proteins. The lack of difference between release rates in the presence of high concentrations of $\mathrm{H}_{2} \mathrm{O}_{2}$ may be a reflection of the fact that maximum rates of protein release rates were achieved with the concentration of $\mathrm{H}_{2} \mathrm{O}_{2}$ used, and that these do not differ between young and old animals. However, this does not preclude the possibility that the sensitivity of protein release to submaximal $\mathrm{H}_{2} \mathrm{O}_{2}$ concentrations may be different. We have previously demonstrated the differential sensitivity of SS and IMF mitochondrial protein release to exogenous, submaximal amounts of $\mathrm{H}_{2} \mathrm{O}_{2}$ (Adhihetty et al., 2005). A similar result may hold for the senescent as compared to young animals; however, this remains to be determined.

It is interesting to compare the extent of the muscle phenotype alterations with age to those of models of muscle disuse, such as chronic denervation. The $60 \%$ decline in muscle mass per unit of body mass evident in 36-month-old animals (Table 1) was matched by a similar extent of atrophy after only 21 days of denervation (Adhihetty et al., 2007a). However, the decrements in mitochondrial content and respiration, PGC-1 $\alpha$, Tfam and MnSOD levels, as well as the increases in ROS production and apoptotic susceptibility were much more pronounced after 21 days of denervation compared to normal innervated muscle at 36 months of age. This is undoubtedly related to the fact that motor unit recruitment and muscular activity is still possible in the aging animal, despite an obvious decline in physical activity levels. This maintained ability for muscle use is likely an important contributor that prevents the large-scale cellular perturbations, and the increase in apoptosis evident with complete muscle disuse, such as with denervation. This suggests the possibility that continuous muscle use, in the form of chronic contractile activity, could attenuate the incidence in apoptosis in muscle. Indeed, we have recently shown that chronic contractile activity attenuates proapoptotic protein release from mitochondria 
(Adhihetty et al., 2007b). This would effectively counteract the augmented protein release that we have observed in 36-monthold animals, as shown in the present study, and suggests the distinct possibility that chronic exercise may be useful in ameliorating at least a portion of the apoptosis-induced decline in muscle mass with age. Further investigation of this promising outcome in aged animals is currently being studied.

In conclusion, our data provide evidence that SS and IMF mitochondria display alterations that contribute to age-induced increases in apoptotic susceptibility. The capacity for ATP production is reduced, as a result of diminished mitochondrial content per gram of muscle. SS mitochondria appear to be more affected than IMF mitochondria, similar to our previous observations with muscle denervation. These data indicate that the sarcopenia and muscle fatigability that accompany advanced stages of senescence are associated with enhanced ROS production, an increase in mitochondrial apoptotic susceptibility, and a reduced transcriptional drive for mitochondrial synthesis.

\section{Experimental procedures}

\section{Animals}

Experiments were conducted after approval by the York University Animal Care Committee in accordance with Canadian Council of Animal Care guidelines. Male Fischer 344 Brown Norway rats were obtained from the National Institute of Aging (Bethesda, MD, USA) and were divided into 6-month (young) and 36-month (senescent) groups. Animals were housed individually and given food and water ad libitum.

\section{In situ stimulation procedure}

Rats were anesthetized with pentobarbital sodium $\left(60 \mathrm{mg} \mathrm{kg}^{-1}\right.$ ) and the left tibialis anterior was exposed and prepared for intramuscular in situ stimulation (Takahashi \& Hood, 1993). Briefly, the distal tendon of the tibialis anterior was isolated and attached to a force transducer, and the tibialis anterior was adjusted to be at resting length. Intramuscular electrodes were placed in the belly of the muscle. The temperature of the stimulated muscle was maintained at $37^{\circ} \mathrm{C}$ with heat lamps and was monitored using a thermistor. Blood pressure was recorded throughout the experimental protocol from a catheter inserted in the left common carotid artery. The tibialis anterior of the other limb was also exposed and wrapped in plastic to prevent tissue dehydration. The experimental protocol involved stimulation with 100 ms trains at $100 \mathrm{~Hz}$ to determine maximal tetanic tension produced by the muscle. This was followed by a stimulation period of 5 min at a frequency of $1 \mathrm{~Hz}$ to evaluate muscle performance during fatigue-inducing conditions. At the end of the acute contractile activity protocol, the gastrocnemius and quadriceps muscles were excised and were used to isolate mitochondrial subfractions. The remaining tissues (heart, soleus and plantaris muscles) were harvested, weighed and clamp frozen in liquid nitrogen.

\section{Mitochondrial isolation}

After excision, mixed gastrocnemius and quadriceps muscles were immediately placed into ice-cold buffer, briefly minced and homogenized. SS and IMF mitochondria were fractionated by differential centrifugation as described previously (Cogswell et al., 1993; Takahashi \& Hood, 1996). Mitochondria were resuspended in resuspension medium $(100 \mathrm{~mm} \mathrm{KCl}, 10 \mathrm{~mm}$ MOPS and $0.2 \%$ defatted BSA). Mitochondrial protein content was determined using the Bradford assay (Bradford, 1976) and the yield was expressed as $\mathrm{mg} \mathrm{g}^{-1}$ muscle wet weight.

\section{Mitochondrial respiration}

Samples of isolated SS and IMF mitochondrial subfractions were incubated with $2 \mathrm{~mL}$ of $\mathrm{VO}_{2}$ buffer $(250 \mathrm{~mm}$ sucrose, $50 \mathrm{~mm} \mathrm{KCl}$, $25 \mathrm{~mm}$ Tris- $\mathrm{HCl}$ and $\left.10 \mathrm{mM} \mathrm{K}_{2} \mathrm{HPO}_{4}, \mathrm{pH} 7.4\right)$ at $30{ }^{\circ} \mathrm{C}$ in a waterjacketed respiratory chamber with continuous stirring. Respiration rates ( $n$ atoms $\mathrm{O}_{2} \mathrm{~min}^{-1} \mathrm{mg}^{-1}$ ) were evaluated in the presence of $10 \mathrm{~mm}$ glutamate (state 4 respiration) or glutamate plus $0.44 \mathrm{~mm}$ adenosine diphosphate (state 3 respiration) using a Clark oxygen electrode (Yellow Springs Instruments, Yellow Springs, OH, USA). The addition of nicotinamide adenine dinucleotide (NADH) during state 3 measurements had no effect on the respiration rate (data not shown), indicating excellent mitochondrial membrane integrity.

\section{ROS production}

Mitochondrial subfractions ( $50 \mu \mathrm{g}$ ) were incubated with $50 \mu \mathrm{M}$ dichlorodihydrofluorescein diacetate $\left(\mathrm{H}_{2} \mathrm{DCFDA}\right)$ and $\mathrm{VO}_{2}$ buffer at $37^{\circ} \mathrm{C}$ in a 96 -well plate. ROS production is directly proportional to fluorescence emission (between 480 and $520 \mathrm{~nm}$ ) measured in a multidetection microplate reader (Synergy HT; Bio-Tek Instruments, Winooski, VT, USA). Microplate data were compiled and analyzed using KC4 software (version 3.0). To assess ROS production during states 3 and 4 respiration, mitochondria were incubated with $10 \mathrm{~mm}$ glutamate or $0.44 \mathrm{~mm}$ adenosine diphosphate before the addition of $\mathrm{H}_{2}$ DCFDA.

\section{$\mathrm{H}_{2} \mathrm{O}_{2}$-induced protein release assay}

Mitochondrial subfractions $(150 \mu \mathrm{g})$ were incubated with

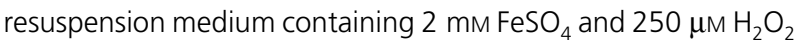
for $60 \mathrm{~min}$ at $30^{\circ} \mathrm{C}$ as described previously (Adhihetty et al., 2005). After a 5-min centrifugation at $14000 \mathrm{~g}\left(4^{\circ} \mathrm{C}\right)$ to pellet mitochondria, the supernatant was collected for cytochrome $c$ and endonuclease $\mathrm{G}$ detection by Western blot analysis.

\section{mtPTP assessment}

As detailed earlier (Adhihetty et al., 2005), mitochondria were resuspended to a final concentration of $1 \mathrm{mg} \mathrm{mL}^{-1}$ in a buffer containing $215 \mathrm{~mm}$ mannitol, $71 \mathrm{~mm}$ sucrose, $3 \mathrm{~mm}$ HEPES and $5 \mathrm{~mm}$ succinate ( $\mathrm{pH}$ 7.4). Maximal mtPTP opening rate (Vmax) and time to Vmax were evaluated after treatment of SS and 
IMF mitochondrial subfractions with $400 \mu \mathrm{M} \mathrm{CaCl}$, and $75 \mu \mathrm{M}$ $t$ - $\mathrm{BuOOH}$, by monitoring the decrease in absorbance spectrophotometrically for $15 \mathrm{~min}$ at $540 \mathrm{~nm}$. This high concentration of calcium is used to produce a calcium overload and evoke the opening of the mtPTP. The kinetics of pore opening using these conditions have been shown to be completely inhibited by the specific mtPTP inhibitor cyclosporin A (Adhihetty et al., 2005).

\section{Flow cytometric analysis of mitochondrial $\Delta \psi$ and cardiolipin content}

Flow cytometry was performed using a four-color FACSCalibur cytometer equipped with a 488-nm argon laser (Becton Dickinson, San Jose, CA, USA). The analysis of SS and IMF mitochondria was performed using data gathered from the forward-angle light scatter and side-angle light scatter detectors. The $\Delta \psi$-insensitive mitochondrial dye Mitotracker Green FM was used to set forward and side scatter gates allowing for the discrimination of mitochondria from the surrounding cellular debris (Lecoeur et al., 2004). Measurement of isolated SS and IMF mitochondrial $\Delta \psi$ was performed using the fluorescent probe $5,5^{\prime}, 6,6^{\prime}$,-tetrachloro-1,1',3,3'-tetraethylbenzimidazolylcarbocyanine iodide (JC-1). A JC-1 stock solution of $1 \mathrm{mg} \mathrm{mL}^{-1}$ in dimethylsulfoxide (DMSO) was diluted in mitochondrial resuspension buffer to a final concentration of $4 \mu \mathrm{g} \mathrm{mL}^{-1}$ and vortexed to avoid aggregate formation. Unenergized mitochondria $\left(0.5 \mathrm{mg} \mathrm{mL}^{-1}\right)$ were incubated with $\mathrm{JC}-1$ working solution for 30 min at $37{ }^{\circ} \mathrm{C}$ in the dark. Reaction mixtures were then centrifuged and resuspended in fresh resuspension medium without JC-1 and analyzed by flow cytometry. The membrane potential measured was completely reduced by preincubation with the uncoupler dinitrophenol. JC-1 monomers were collected in the green FL-1 channel (530/30 nm). JC-1 red fluorescence, caused by the formation of J-aggregates, was measured using the FL-2 channel (585/21 nm).

Mitochondrial cardiolipin content was measured using the fluorescent probe 10-N-Nonyl-3,6-bis(dimethylamino) acridine orange (NAO). An NAO stock solution of $50 \mathrm{~mm}$ in DMSO was diluted in mitochondrial resuspension buffer to a final concentration of $10 \mathrm{~nm}$. Mitochondria $\left(0.5 \mathrm{mg} \mathrm{mL}^{-1}\right)$ were incubated with NAO working solution for $15 \mathrm{~min}$ at $37^{\circ} \mathrm{C}$ in the dark. Samples were then centrifuged and resuspended in fresh resuspension medium without NAO and analyzed using the flow cytometer. NAO green fluorescence was measured using the FL-1 channel (530/30 nm). All analyzed flow cytometric data were derived from at least 20000 gated events.

\section{Enzyme activities}

COX activity was measured as previously described (Gordon et al., 2001). Enzyme activity was determined as the maximal rate of oxidation of fully reduced cytochrome $c$ at $550 \mathrm{~nm}$ in a multidetection microplate reader (Synergy HT; Bio-tek Instruments, Winooski, VT, USA). CS activity was measured according to Reichmann et al. (1983).

\section{Immunoblotting}

Whole muscle homogenates, isolated mitochondrial protein extracts, cytosolic fractions, or supernatant aliquots from the protein release assay were separated by performing 10-15\% sodium dodecyl sulphate-polyacrylamide gel electrophoresis (SDS-PAGE) and subsequently electroblotted onto nitrocellulose membranes. After transfer, membranes were blocked (1 h) with a $5 \%$ skim milk in $1 \times$ TBST (Tris-buffered saline-Tween-20: $25 \mathrm{~mm}$ Tris- $\mathrm{HCl}, \mathrm{pH} 7.5,1 \mathrm{~mm} \mathrm{NaCl}$ and $0.1 \%$ Tween-20) solution. Blots were then incubated in blocking solution with antibody directed against cytochrome $c$ (1: 1000 dilution), AIF (1: 1000 dilution), endonuclease $\mathrm{G}(1: 500$ dilution), MnSOD ( $1: 2000$ dilution), ANT, $1: 2000$ dilution), VDAC (1: 3000 dilution) cyclophilin $D(1: 400$ dilution), mitochondrial transcription factor A (Tfam, $1: 500$ dilution), PGC-1 $\alpha$ (1: 500 dilution in 10\% skim milk/TBST), Ogg1 (1: 750 dilution), Aciculin (1 : 200 dilution) or glyceraldehyde-3 phosphate dehydrogenase (GAPDH, $1: 50000$ dilution) overnight at $4{ }^{\circ} \mathrm{C}$. After three 5 -min washes with TBST, blots were incubated at room temperature (1 h) with the appropriate secondary antibody coupled to horseradish peroxidase and washed again three times for 5 min each with TBST. Antibody-bound protein was revealed using the enhanced chemiluminescent method. Films were scanned and analyzed using SigmaScanPro 4 (Jandel Scientific, San Rafael, CA, USA).

\section{Statistical analyses}

Data are expressed as means $\pm \mathrm{SE}$. Comparisons between 6month-old and 36-month-old animals were made using Student's $t$-tests or two-way analysis of variance (age vs. mitochondrial subfraction or muscle type) followed by Bonferroni post hoc tests, where appropriate. Statistical differences were considered significant at $P<0.05$.

\section{Acknowledgments}

This work was supported by the Natural Sciences and Engineering Research Council of Canada (NSERC) and the Canadian Institutes of Health Research. The authors are grateful to Dr. Peter Adhihetty for his assistance throughout this study. Vladimir Ljubicic was a recipient of an NSERC Postgraduate Scholarship, and is currently funded by a Doctoral Research Award from the Heart and Stroke Foundation of Canada. David A. Hood holds a Canada Research Chair in Cell Physiology.

\section{References}

Adhihetty PJ, Hood DA (2003) Mechanisms of apoptosis in skeletal muscle. Basic Appl. Myol. 13, 171-179.

Adhihetty PJ, Ljubicic V, Menzies KJ, Hood DA (2005) Differential susceptibility of subsarcolemmal and intermyofibrillar mitochondria to apoptotic stimuli. Am. J. Physiol. Cell Physiol. 289, C994-C1001.

Adhihetty PJ, O'Leary MF, Chabi B, Wicks KL, Hood DA (2007a) Effect of denervation on mitochondrially mediated apoptosis in skeletal muscle. J. Appl. Physiol. 102, 1143-1151. 
Adhihetty PJ, Ljubicic V, Hood DA (2007b) Effect of chronic contractile activity on SS and IMF mitochondrial apoptotic susceptibility in skeletal muscle. Am. J. Physiol. Endocrinol. Metab. 292, E748-E755.

Barrientos A, Casademont J, Rotig A, Miro O, Urbano-Marquez A, Rustin P, Cardellach F (1996) Absence of relationship between the level of electron transport chain activities and aging in human skeletal muscle. Biochem. Biophys. Res. Commun. 229, 536-539.

Bezaire V, Heigenhauser GJ, Spriet LL (2004) Regulation of CPT I activity in intermyofibrillar and subsarcolemmal mitochondria from human and rat skeletal muscle. Am. J. Physiol. Endocrinol. Metab. 286, E85E91.

Bizeau ME, Willis WT, Hazel JR (1998) Differential responses to endurance training in subsarcolemmal and intermyofibrillar mitochondria. J. Appl. Physiol. 85, 1279-1284.

Bradford MM (1976) A rapid and sensitive method for the quantitation of microgram quantities of protein utilizing the principle of proteindye binding. Anal. Biochem. 72, 248-254.

Bua EA, McKiernan SH, Wanagat J, McKenzie D, Aiken JM (2002) Mitochondrial abnormalities are more frequent in muscles undergoing sarcopenia. J. Appl. Physiol. 92, 2617-2624.

Chung L, Ng YC (2006) Age-related alterations in expression of apoptosis regulatory proteins and heat shock proteins in rat skeletal muscle. Biochim. Biophys. Acta 1762, 103-109.

Cogswell AM, Stevens RJ, Hood DA (1993) Properties of skeletal muscle mitochondria isolated from subsarcolemmal and intermyofibrillar regions. Am. J. Physiol. 264, C383-C389.

Conley KE, Jubrias SA, Esselman PC (2000) Oxidative capacity and ageing in human muscle. J. Physiol. 526, 203-210.

Cortina MS, Gordon WC, Lukiw WJ, Bazan NG (2005) Oxidative stressinduced retinal damage up-regulates DNA polymerase gamma and 8-oxoguanine-DNA-glycosylase in photoreceptor synaptic mitochondria. Exp. Eye Res. 81, 742-750.

Dirks AJ, Hofer T, Marzetti E, Pahor M, Leeuwenburgh C (2006) Mitochondrial DNA mutations, energy metabolism and apoptosis in aging muscle. Ageing Res. Rev. 5, 179-195.

Dirks A, Leeuwenburgh C (2002) Apoptosis in skeletal muscle with aging. Am. J. Physiol. Regul. Integr. Comp. Physiol. 282, R519-R527.

Dirks AJ, Leeuwenburgh C (2004) Aging and lifelong calorie restriction result in adaptations of skeletal muscle apoptosis repressor, apoptosisinducing factor, X-linked inhibitor of apoptosis, caspase-3, and caspase-12. Free Radic. Biol. Med. 36, 27-39.

Drew B, Phaneuf S, Dirks A, Selman C, Gredilla R, Lezza A, Barja G, Leeuwenburgh $C$ (2003) Effects of aging and caloric restriction on mitochondrial energy production in gastrocnemius muscle and heart. Am. J. Physiol. Regul. Integr. Comp. Physiol. 284, R474-R480.

Fannin SW, Lesnefsky EJ, Slabe TJ, Hassan MO, Hoppel CL (1999) Aging selectively decreases oxidative capacity in rat heart interfibrillar mitochondria. Arch. Biochem. Biophys. 372, 399-407.

Farrar RP, Martin TP, Ardies CM (1981) The interaction of aging and endurance exercise upon the mitochondrial function of skeletal muscle. J. Gerontol. 36, 642-647.

Gordon JW, Rungi AA, Inagaki H, Hood DA (2001) Effects of contractile activity on mitochondrial transcription factor $A$ expression in skeletal muscle. J. Appl. Physiol. 90, 389-396.

Green DR, Reed JC (1998) Mitochondria and apoptosis. Science 281, 1309-1312.

Hagen JL, Krause DJ, Baker DJ, Fu MH, Tarnopolsky MA, Hepple RT (2004) Skeletal muscle aging in $\mathrm{F} 344 \mathrm{BN} \mathrm{F}_{1}$-hybrid rats. I. Mitochondrial dysfunction contributes to the age-associated reduction in $\mathrm{VO}_{2 \max }$. J. Gerontol. A Biol. Sci. Med. Sci. 59, 1099-1110.

Irrcher I, Adhihetty PJ, Joseph AM, Ljubicic V, Hood DA (2003) Regulation of mitochondrial biogenesis in muscle by endurance exercise. Sports Med. 33, 783-793.
Judge S, Jang YM, Smith A, Hagen T, Leeuwenburgh C (2005) Ageassociated increases in oxidative stress and antioxidant enzyme activities in cardiac interfibrillar mitochondria: implications for the mitochondrial theory of aging. FASEB J. 19, 419-421.

Koves TR, Noland RC, Bates AL, Henes ST, Muoio DM, Cortright RN (2005) Subsarcolemmal and intermyofibrillar mitochondria play distinct roles in regulating skeletal muscle fatty acid metabolism. Am. J. Physiol. Cell Physiol. 288, C1074-C1082.

Lecoeur H, Langonne A, Baux L, Rebouillat D, Rustin P, Prevost MC, Brenner C, Edelman L, Jacotot E (2004) Real-time flow cytometry analysis of permeability transition in isolated mitochondria. Exp. Cell Res. 294, 106-117.

Lezza AM, Pesce V, Cormio A, Fracasso F, Vecchiet J, Felzani G, Cantatore P, Gadaleta MN (2001) Increased expression of mitochondrial transcription factor $A$ and nuclear respiratory factor- 1 in skeletal muscle from aged human subjects. FEBS Lett. 501, 74-78.

Ljubicic V, Adhihetty PJ, Hood DA (2004) Role of UCP3 in state 4 respiration during contractile activity-induced mitochondrial biogenesis. J. Appl. Physiol. 97, 976-983.

Martin C, Dubouchaud H, Mosoni L, Chardigny JM, Oudot A, Fontaine E, Vergely C, Keriel C, Rochette L, Leverve X, Demaison L (2007) Abnormalities of mitochondrial functioning can partly explain the metabolic disorders encountered in sarcopenic gastrocnemius. Aging Cell 6, 165-177.

Mo J, Xia Y, Wade TJ, Schmitt M, Le XC, Dang R, Mumford JL (2006) Chronic arsenic exposure and oxidative stress: OGG1 expression and arsenic exposure, nail selenium, and skin hyperkeratosis in Inner Mongolia. Environ. Health Perspect. 114, 835-841.

Mosoni L, Malmezat T, Valluy MC, Houlier ML, Attaix D, Mirand PP (1999) Lower recovery of muscle protein lost during starvation in old rats despite a stimulation of protein synthesis. Am. J. Physiol. 277, E608-E616.

Nakabeppu Y, Tsuchimoto D, Furuichi M, Sakumi K (2004) The defense mechanisms in mammalian cells against oxidative damage in nucleic acids and their involvement in the suppression of mutagenesis and cell death. Free Radic. Res. 38, 423-429.

Rasmussen UF, Krustrup P, Kjaer M, Rasmussen HN (2003) Human skeletal muscle mitochondrial metabolism in youth and senescence: no signs of functional changes in ATP formation and mitochondrial oxidative capacity. Pflugers Arch. 446, 270-278.

Reichmann H, Srihari T, Pette D (1983) Ipsi- and contralateral fibre transformations by cross-reinnervation. A principle of symmetry. Pflugers Arch. 397, 202-208.

Rice KM, Blough ER (2006) Sarcopenia-related apoptosis is regulated differently in fast- and slow-twitch muscles of the aging F344/N $\times$ BN rat model. Mech. Ageing Dev. 127, 670-679.

Risom L, Moller P, Vogel U, Kristjansen PE, Loft S (2003) X-ray-induced oxidative stress: DNA damage and gene expression of HO-1, ERCC1 and OGG1 in mouse lung. Free Radic. Res. 37, 957-966.

Siu PM, Alway SE (2005) Mitochondria-associated apoptotic signalling in denervated rat skeletal muscle. J. Physiol. 565, 309-323.

Siu PM, Pistilli EE, Alway SE (2005) Apoptotic responses to hindlimb suspension in gastrocnemius muscles from young adult and aged rats. Am. J. Physiol. Regul. Integr. Comp. Physiol. 289, R1015R1026.

Takahashi M, Hood DA (1993) Chronic stimulation-induced changes in mitochondria and performance in rat skeletal muscle. J. Appl. Physiol. 74, 934-941.

Takahashi M, Hood DA (1996) Protein import into subsarcolemmal and intermyofibrillar skeletal muscle mitochondria. Differential import regulation in distinct subcellular regions. J. Biol. Chem. 271, 27285-27291.

Tonkonogi M, Fernstrom M, Walsh B, Ji LL, Rooyackers O, Hammarqvist F, 
12 Subsarcolemmal and intermyofibrillar mitochondria in aged skeletal muscle, B. Chabi et al.

Wernerman J, Sahlin K (2003) Reduced oxidative power but unchanged antioxidative capacity in skeletal muscle from aged humans. Pflugers Arch. 446, 261-269.

Trounce I, Byrne E, Marzuki S (1989) Decline in skeletal muscle mitochondrial respiratory chain function: possible factor in ageing. Lancet 8639, 637-639.

Turturro A, Witt WW, Lewis S, Hass BS, Lipman RD, Hart RW (1999)
Growth curves and survival characteristics of the animals used in the biomarkers of aging program. J. Gerontol. A Biol. Sci. Med. Sci. 54, B492-B501.

Wanagat J, Cao Z, Pathare P, Aiken JM (2001) Mitochondrial DNA deletion mutations colocalize with segmental electron transport system abnormalities, muscle fiber atrophy, fiber splitting, and oxidative damage in sarcopenia. FASEB J. 15, 322-332. 